\title{
GPS-BASED FRAMEWORK TOWARDS MORE REALISTIC AND REAL-TIME CONSTRUCTION EQUIPMENT OPERATION SIMULATION
}

\author{
Nipesh Pradhananga \\ Jochen Teizer \\ School of Civil and Environmental Engineering \\ Georgia Institute of Technology \\ 790 Atlantic Dr. N.W., Atlanta, GA 30332-0355, USA
}

\begin{abstract}
This paper presents an automated GPS-based method for assessing construction equipment operations productivity. The literature revealed several shortcomings in simulation of construction equipment, for example, the availability of realistic data that supports a simulation framework, and identified the need for integrating real-time field data into simulations. Commercially available GPS-based data logging technology was then evaluated. Analysis methods and rules for monitoring productivity were also discussed. A software interface was created that allowed to analyze and visualize several important parameters towards creating more realistic simulation models. The experimental results showed a productivity assessment method by collecting spatio-temporal data using GPS data logging technology, applied to construction equipment operations, and finally identified and tracked productivity and safety based information for job site layout decision making. This research aids construction project managers in decision making for planning work tasks, hazard identification, and worker training by providing realistic and real-time project equipment operation information.
\end{abstract}

\section{$1 \quad$ INTRODUCTION}

Outdoor construction jobsites are dynamic environments in which construction resources (workers, equipment, and materials) continuously interact with each other. Recording these interactions is critical for analyzing any construction operation. The activity analysis method proposed by the Construction Industry Institute (2010) provides a method for observing, recording, and analyzing work tasks on construction jobsites. This method focuses on productivity analysis and less suited to identify locations that contain hazardous conditions. The method also uses manual sampling methods and is incapable of collecting data continuously.

Introducing technology to automatically record the location of construction resources at a jobsite can simplify assessment of work tasks and improve reliability of measurement (Cheng et al. 2010). Real-time tracking of construction resources has been accomplished using different emerging technologies (e.g., Radio Frequency Identification (RFID), Ultra Wideband (UWB), image based systems and video are other examples of emerging technologies used on construction sites for tracking (Costin et al. 2012; Cheng et al. 2010; Chi and Caldas 2012). Similarly, fusion of multiple sensors for real-time resource tracking has also been tested (Razavi and Haas 2010).

However, Global Positioning System (GPS) is the only known independent location tracking technique for construction equipment that does not require pre-installed infrastructure (Behzadan et al. 2008). This paper presents the implementation of GPS units for tracking construction equipment as it relates to cyclic activities common in earth moving operations. 


\section{BACKGROUND}

Hinze (2005) found that most injury rate measures used to evaluate safety performance are lagging indicators of safety and do not provide insights on the existing safety conditions. However, as measurement of leading indicators has begun, continuous data collection and data analysis has the potential to impact more rapidly the safety conditions on a construction jobsite. A theory is, if safety data would rapidly update, safety personnel could take preventive actions and prevent hazardous conditions from occurring. A common safety goal is to put adequate effort in place to achieve the goal of zero injuries; then every injury is preventable. Since the construction industry has yet to recognize existing risks rapidly (and in realtime), data is often gathered after-the-fact (Fosbroke 2004, Teizer et al. 2010). Technology exists that is capable of tracking real time spatio-temporal information. Often decision makers do not understand technology or investment-benefit. Cost, maintenance, size, scalability, reliability, data update rate and social impact of the technology are often criteria that are applied in decision making of implementing technology (Cheng et al. 2010) .

Oloufa et al. (2002) developed a collision detection system for construction equipment using GPS technology. Real-Time Kinematic (RTK) GPS has been used for controlling vertical accuracy of the earth's surface profiling and automated information reporting (Peyret et al. 2000, Li et al. 2005). The system consisted of a centralized monitoring system for waste management.

Commercial products exist that utilize highly precise GPS technology for outdoor applications such as in accurate agricultural, construction, and transportation (Ruß and Brenning 2010; Zheng et al. 2012; Cat 2012). Some recent academic studies focused on the analysis of GPS data for construction operations analysis (Hildreth et al. 2005) and tunnel construction utilizing iPhone and Personal Digital Assistant (PDA) technology for data collection (Xie et al. 2011). These, however, do not focus on continuous location data sensing as it could be applied in simulation models.

\section{OBJECTIVES AND SCOPE}

This research focuses on implementing commercially-available stand-alone GPS units to track critical construction equipment on a real construction jobsite. There are two major objectives of this research: (1) to evaluate the performance of the technology in a simulated and rugged construction environment and (2) to illustrate how continuous tracking data obtained from this technology can be utilized to reflect the utilization rate of construction equipment on a job site. This research implemented low cost GPS data loggers which require no pre-installed infrastructure. More accurate GPS technologies are available in the market, but the researchers' intent was to implement a technology that requires little investment in cost

(e.g., purchase or maintenance) and time (e.g., installation). This research does also not account for the limitations of some of the commercially-existing GPS data loggers, e.g., manual downloading of data at the end of the day. A platform was developed for visualizing and analyzing the collected data. The observed scenarios involved excavation and earth moving. Only critical construction equipment involving motion and interaction with other equipment on site were tagged. Limited by the technology, this research only dealt with an outdoor construction environment.

\section{RESEARCH OUTLINE}

The research outline is shown in the flowchart in Figure 1. Before deploying the technology, an error analysis was completed to evaluate the system's performance in different environmental conditions. Instrumental error can play a significant role in experimental design and analysis of data. Data was then collected by installing the GPS data loggers on various pieces of construction equipment. The obtained continuous location data was fed into and processed by an analysis platform developed by the researchers. The analysis platform incorporated the site layout with the recorded spatio-temporal data for reporting valuable results regarding equipment utilization on the job site. These steps are described in the following sections. 


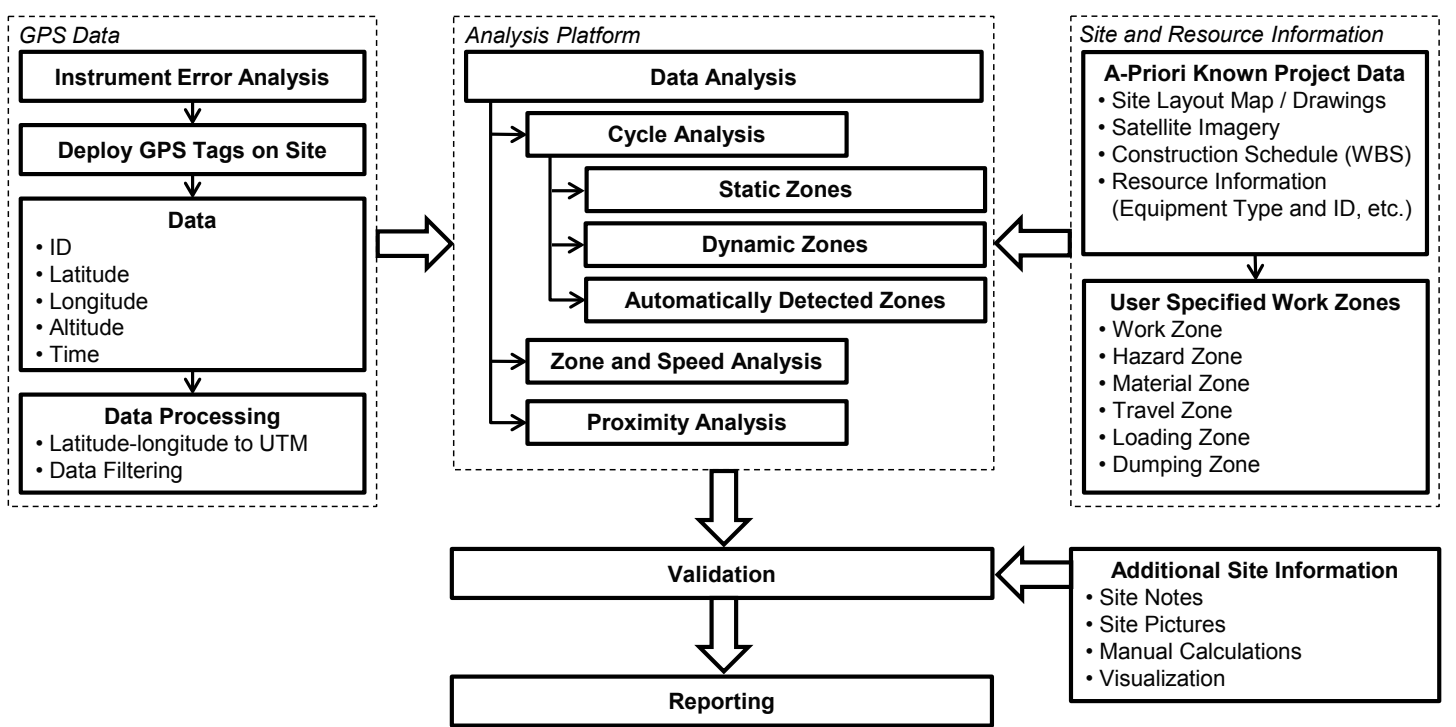

Figure 1: Research outline.

\subsection{Instrument Error Analysis}

Commercially-available Wintec G-Rays 2 data loggers were used in this research. The data was collected in a continuous manner. The GPS unit was also equipped with a motion sensor to avoid recording redundant data when the unit was not moving. The accuracy of the units was tested in two scales: absolute global scale and relative scale. Absolute scale is the measure of correctness of the global coordinates logged by the units. Relative scale is the measure of deviations exhibited by the units when exposed to the same environmental conditions. Since multiple GPS data loggers were deployed on the same construction site at the same time, knowing its relative accuracy can give a good sense of the level of accuracy to be expected while studying the problem of spatio-temporal interaction of the construction resources.

The measure of accuracy of the units in absolute scale was done by comparing the coordinate logged by the unit to a known coordinate point (see Figure 2a). As shown in Figure 2b, ten GPS data loggers were placed in two rows (five units in each row) on a wood board. The distance from the center of the board to the center of each of the units was measured manually with a tape (to later relate the GPS loggers' position back to the benchmark point). The wooden board was oriented to the north for proper correction of these offsets. A guiding rectangle was marked around the benchmark point so that the center of the board coincides with the center of the benchmark point (Figure 2b). Readings were taken on all ten units. This process was repeated a total of 36 times. The experiment was conducted on a day with no precipitation and minimal cloud cover. Similar experiment on relative accuracy was conducted at a construction site located at Georgia Tech's campus (figure 2c). The selected site for the GPS data logger error analysis was different from the case study site that will be presented later in this paper.

(a)

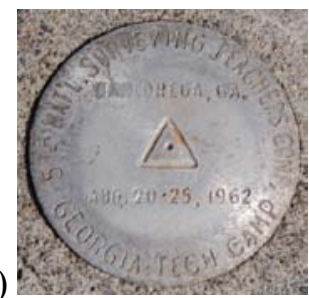

(b)

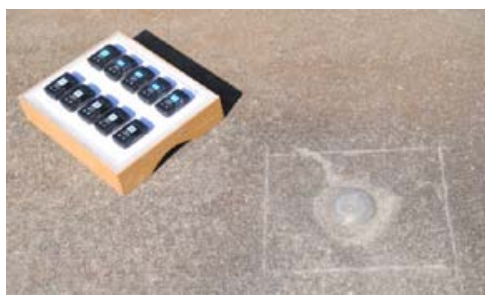

(c)

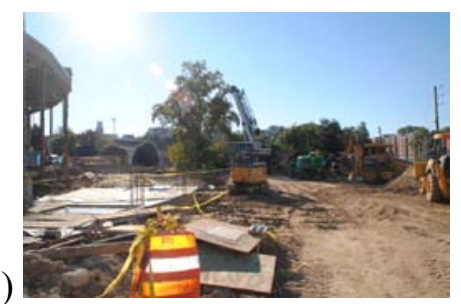

Figure 2: (a) Benchmark point DG 2790, (b) Apparatus setup for test, and (c) Field trial setting. 


\section{Pradhananga and Teizer}

\subsection{Data Collection and Processing}

A case study was performed to collect continuous GPS data with the loggers. Ten GPS units were used. Each unit was set to its highest possible accuracy mode. The data logging frequency was $1 \mathrm{~Hz}$. The GPS units were installed inside the equipment at the spot with maximum exposure to the sky (Figure 3a). Some pieces of construction equipment were tagged with two units for redundancy and relative error analysis (Figure 3b). Figure 3c shows a plot of the trajectory of an excavator during the course of a day using two data loggers. Data was collected for an entire work shift which ranged from four to more than twelve hours per day.

(a)

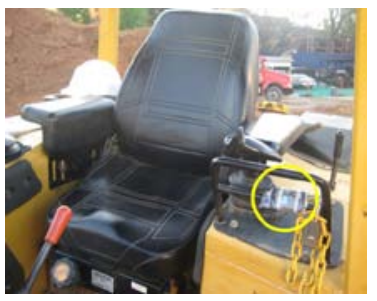

(b)

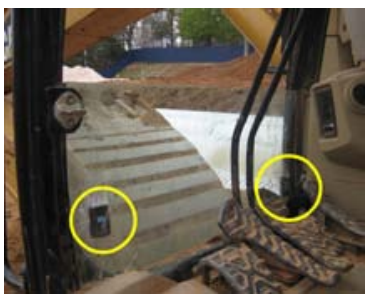

(c)

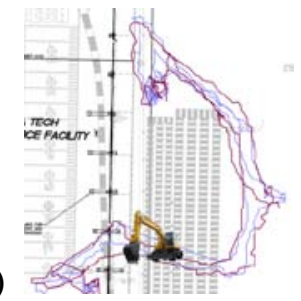

Figure 3: (a) GPS data logger mounted on a loader, (b) two units mounted inside an excavator, and (c) plan view of trajectory and orientation of the excavator.

Data was downloaded for each data logger in Comma Separated Value (CSV) format. The data was changed from latitude-longitude to Universal Transverse Mercator (UTM) for ease in computing and visualization. Reading the raw data file and assigning it to a data logger is done by a user interface discussed below. While importing the data into the system, it was initially filtered using a Robust Kalman Filter. Kalman filter has been widely used for filtering navigation data. Robust Kalman Filter also rejects outliers in addition to smoothing the signal.

\subsection{Data Analysis}

A platform was developed in Visual C\# 2010 for data visualization and analysis (Figure 4). A Matlab API was created for complex matrix manipulations. Raw data was imported into the platform using a user interface. Data was filtered and stored in a Microsoft Access (.mdb) database.

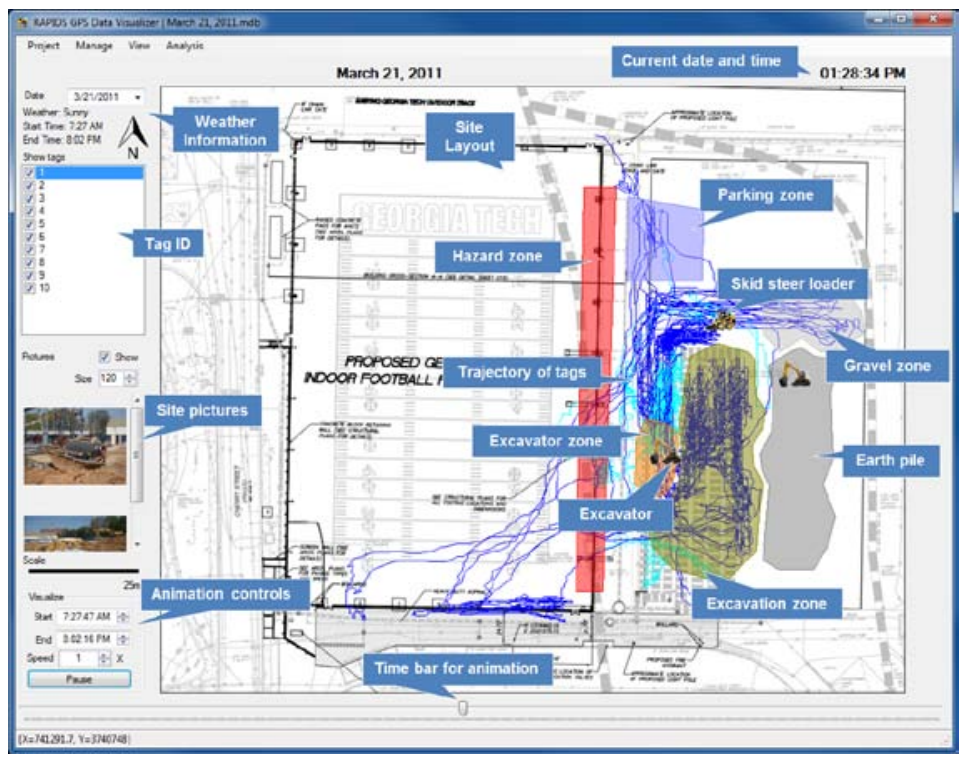

Figure 4: User interface to display GPS data and other site and project management relevant information. 


\section{Pradhananga and Teizer}

An image and a separate color can be assigned to each data logger and trajectories of the data logger(s) can be plotted in specified color(s). Real-time animation showing the data logger movements can be visualized. Figure 4 shows the basic user interface that was developed. The background image was the site layout map which can be imported and plotted into the interface by specifying the top left and bottom right coordinates. Trajectory of the data loggers can be plotted on top of the site layout and the image selected will be displayed to represent the position of the data logger at selected time. Photos were taken from the site while monitoring the resources with the GPS data loggers. These photos can be loaded and displayed in left part of the interface. The photos corresponded to the current action on site and in time of the animation.

\section{Analysis of Cyclic Activities}

Cyclic activities are common in construction operations. A typical construction equipment cycle consists of four components: load time, haul time, unload time, and return time. Load time is the time spent by the equipment loading material. Haul time is the travel time from start zone (loading zone) to end zone (unloading zone). Unload time is the time taken by the equipment to dump the material and return time is the time it takes the equipment to travel from the dump zone back to the loading zone. Such cyclic activities can be automatically identified and analyzed using continuous data. The amount of material hauled can also be estimated if the capacity of the equipment is considered. Such data can then be used for equipment productivity analysis. This research only addresses the identification and analysis of equipment cycles. The following cases are used to determine a cycle:

Fixed zone to fixed zone: This analysis involves cyclic construction operations made from a fixed zone to another fixed zone on a site layout map. It means the starting and ending point of the cycle does not change as the operation continues.

Fixed zone to dynamic zone: This type of cycle is very common in linear repetitive projects like highway, pipeline work, canals etc. Cycles are made between a static fixed zone and another zone that changes its position over time. A static zone can be represented by the zones a user draws on the site layout map. The position of the dynamic zone is determined by a GPS data logger that is attached to the resource who changes its position. A radius the user decides specifies size of the dynamic zone.

Dynamic zone to dynamic zone: This analysis involves cycles made between a dynamic to another dynamic zone. The position of both zones change over time and travels made between these zones are analyzed each time based on the position of the zones at that instance of time.

\section{Zone and Speed Analysis}

Knowing the distribution of time spent by equipment in different zones can give a good understanding on its utilization. Equipment trajectories can be traced to see how often a piece of equipment entered a specified zone and how much time it spent in that zone. Another interesting piece of information construction managers liked to know was the speed equipment travels in different zones. Equipment traveling at a higher-than-normal (or user-specified) speed inside a hazardous work environment/zone would be considered unsafe. Also, internal traffic control (ITC) plans should be designed in such a way that construction equipment should enter hazardous zones at minimal number of times and spent as less time as possible in such zones.

\section{Proximity Between Two Resources}

Equipment working close to each other can cause hazards. Present methods of recording construction operations can record collisions after they occur. But, cases of near misses cannot be recorded without continuous recording of data. Since the locations of equipment are known at each time frame, proximity analysis can be done which can be used to identify cases where equipment operate closer to each other than the allowable threshold. By specifying a threshold distance and equipment, the number of times this proximity threshold is breached within a certain timeframe can be exactly determined. The time when they get closest to each other and the distance when they are closest to each other can also be determined. 


\section{Pradhananga and Teizer}

EXPERIMENTS AND RESULTS

Experiments conducted for instrument error analysis and implementation of technology in construction environment as discussed below. Figure $2 \mathrm{c}$ shows the scenery where the GPS data logging units were tested. Results to each of the experiments are presented under their corresponding headings.

\subsection{Instrument Error Analysis}

The GPS data logging units were compared to the benchmark point. The maximum and minimum distances between the actual coordinate and the coordinate read by the data loggers was $1.36 \mathrm{~m}$ and $0.87 \mathrm{~m}$. The overall mean of the distances was $1.10 \mathrm{~m}$ and the standard deviation was $0.41 \mathrm{~m}$. The standard deviation was high compared to the value of the mean indicating high deviation of individual values from the mean. For the construction jobsite case study, data loggers installed inside construction equipment and hardhats could be obstructed by other construction resources such as overhead equipment cabins or materials. Overhead obstructions including roof positions or worker's head pose orientation continuously changes the exposure of the data logger to the sky. Such accuracy cannot be expected on a construction site. The later experiments will demonstrate the relative accuracy among the data loggers in such conditions.

An active construction site was chosen as the second site to test the units in a rugged construction environment. A facility was being built just next to the test point and there were buildings located on the other side of the construction site. There were numerous construction equipment and trees around the point simulating the environment of real data collection. This site was chosen to demonstrate the performance of the data loggers in a congested construction environment where the view of sky is limited. Figure $2 \mathrm{c}$ shows the working condition for this point. The analysis also showed a higher deviation compared to previous case. The mean deviation was found to be $2.15 \mathrm{~m}$ which is significantly higher than the previous case. The maximum and minimum deviations was seen to be $4.36 \mathrm{~m}$ and $0.68 \mathrm{~m}$.

Hence, the GPS data loggers were found to perform better under clear view of sky while the performance degraded with increasing obstacles. Standard deviations were high compared to the value of mean in all cases indicating that the readings were not consistent and can vary significantly. It should be understood that error level can change between data loggers. The above tests give a general idea about the extent of accuracy that can be obtained from the data logging units.

\subsection{Data Collection}

The case study was done for several construction activities including earthmoving operations and pipe installation for a water management facility. A total of 1,400 linear feet of corrugated metal pipes (diameters of 72 inches and 96 inches) were installed with excavation depth ranging from 16-20ft. This system was used for collecting rain water for irrigation purposes. Construction equipment used in this operation was two excavators, one loader, one dozer, and one skid steer loader. Different combinations of tagging the data loggers to the equipment were done on different days depending on the construction schedule. For construction equipment with open cabins such as a compactor, the equipment operator was tagged instead of the piece of equipment.

\subsection{Results to Automatic Analysis of Cyclic Activities}

Fixed Zone to Fixed Zone (defined by a user, manually)

An example of cycles made between two fixed zones has been shown in Figure 5. In this case, a skid steer delivering gravel from a storage zone to a backfilling zone is considered. A zone named "gravel" has been defined by drawing a polygon over the site layout map using the developed user interface. An excavator is located at the backfilling zone. Since the excavator does not move during the course of data recording, a fixed static zone can be assigned to the backfilling area. Hence, a zone named "excavator" has been defined for this case. 


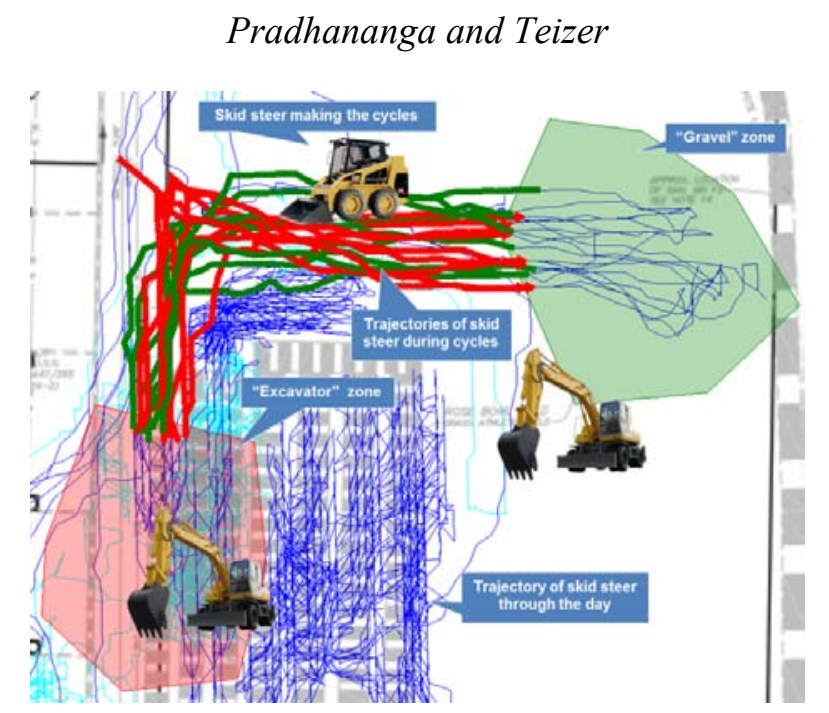

Figure 5: Cycle analysis - fixed to fixed zone (green and red).

Table 1 shows the results of the cycles a skid steer loader made between these two zones. "Start time" and "end time" indicate the time when the skid steer loader leaves one zone to travel to the other. The "direction of travel" indicates the traveling direction between the zones. "Return time" in this case represents the time it took the skid steer loader to travel from "excavator" to "gravel" after unloading gravel at "excavator" for backfilling. Similarly, "haul time" indicates the time it took the skid steer loader to travel from "gravel" to "excavator" (carrying gravel). "Cycle time" is the time it took the skid steer loader to complete one full cycle. "Unloading time" and "loading time" are the times the skid steer loader spent inside "excavator" and "gravel" zones, respectively.

Table 1: Cycle analysis - fixed zone to fixed zone.

\begin{tabular}{|c|c|c|c|c|c|c|c|c|c|c|c|}
\hline 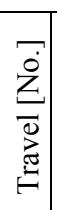 & $\begin{array}{c}\text { Start time } \\
\text { [HH:MM:SS] }\end{array}$ & $\begin{array}{c}\text { End time } \\
{[\mathrm{HH}: \mathrm{MM}: \mathrm{SS}]}\end{array}$ & $\begin{array}{l}\text { Direction of } \\
\text { travel } \\
{[\text { From } \rightarrow \text { To }]}\end{array}$ & 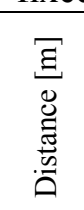 & 甾焉 & 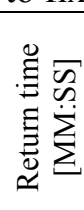 & 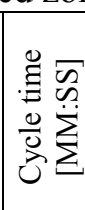 & 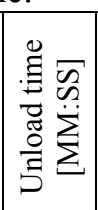 & 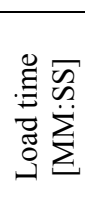 & 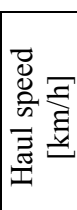 & 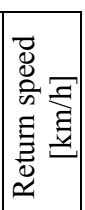 \\
\hline \multirow[b]{2}{*}{1} & 01:17:48 PM & 1:18:14 PM & Gravel $\rightarrow$ Excavator & 43.20 & $00: 26$ & & $01: 51$ & & - & 5.98 & \\
\hline & 01:18:42 PM & 01:19:11 PM & Gravel $<$ Excavator & 50.28 & & $00: 29$ & & $00: 28$ & & & \begin{tabular}{|l|}
6.23 \\
\end{tabular} \\
\hline \multirow{2}{*}{2} & $01: 19$ & 01:20:05 PM & Gravel $\rightarrow$ Excavator & 44.48 & $00: 26$ & & $01: 35$ & & $00: 28$ & 6.16 & \\
\hline & $01: 20$ & $5 \mathrm{PM}$ & Gravel $\leftarrow \mathrm{E}$ & 45.92 & & $00: 26$ & & $00: 14$ & & & 6.37 \\
\hline \multirow{2}{*}{3} & $01: 21: 14 \mathrm{PM}$ & 01:21:41 PM & Gravel $\rightarrow$ Excavator & 47.83 & $00: 27$ & & $01: 31$ & & $00: 29$ & \begin{tabular}{|l|l|}
6.37 \\
\end{tabular} & \\
\hline & 01:21:51 PM & 01:22:19 PM & Gravel<Excavator & 47.87 & & $00: 28$ & & $00: 10$ & & & 6.16 \\
\hline \multirow{2}{*}{4} & 01:22:45 PM & 01:23:19 PM & Gravel $\rightarrow$ Excavator & 43.23 & $00: 34$ & & $01: 54$ & & $00: 26$ & 4.57 & \\
\hline & 01:23:43 PM & 01:24:14 PM & Gravel $<$ Excavator & 43.33 & & $00: 31$ & & $0: 24$ & & & 5.04 \\
\hline \multirow{2}{*}{5} & 01:24:39 PM & 01:25:06 PM & Gravel $\rightarrow$ Excavator & 44.93 & $00: 27$ & & 02:07 & & $00: 25$ & \begin{tabular}{|l|l|}
5.98 \\
\end{tabular} & \\
\hline & $01: 2$ & & Grave & 48.17 & & $00: 32$ & & $00: 30$ & & & 5.44 \\
\hline \multirow{2}{*}{6} & $01: 26: 46 \mathrm{PM}$ & $01: 27: 13 \mathrm{PM}$ & Gravel $\rightarrow$ Excavator & 46.37 & $00: 27$ & & $01: 40$ & & $00: 38$ & 6.19 & \\
\hline & 01:27:30 PM & 01:28:02 PM & Gravel<Excavator & 49.20 & & $00: 32$ & & $00: 17$ & & & 5.54 \\
\hline \multirow{2}{*}{7} & $01: 2$ & PM & Gravel & 45.13 & $00: 28$ & & $01: 50$ & & $00: 24$ & 5.80 & \\
\hline & $01: 2$ & M & Gravel $\leftarrow$ & 51.22 & & $00: 29$ & & $00: 18$ & & & 6.37 \\
\hline \multirow{2}{*}{8} & $01: 30$ & $: 30: 50 \mathrm{PM}$ & Gravel $\rightarrow$ Excavator & 47.78 & $00: 34$ & & $01: 53$ & & $00: 35$ & 5.08 & \\
\hline & 01:31:05 PM & 01:31:39 PM & Gravel<Excavator & 54.31 & & $00: 34$ & & $0: 15$ & & & 5.76 \\
\hline \multirow{5}{*}{9} & & & Gravel $\rightarrow$ Excavator & 47.49 & $00: 28$ & & - & & $00: 30$ & 6.12 & \\
\hline & $01: 33$ & $01: 34: 2$ & Gravel $<$ Excavator & 55.04 & & $00: 56$ & & $0: 48$ & & & 3.53 \\
\hline & & & Min & & $00: 26$ & $00: 26$ & $01: 31$ & $00: 10$ & $00: 24$ & 4.57 & 3.53 \\
\hline & & & $\operatorname{Max}$ & & $00: 34$ & $00: 56$ & 02:07 & $00: 48$ & $00: 38$ & \begin{tabular}{|l|l|}
6.37 \\
\end{tabular} & 6.37 \\
\hline & & & Average & & $00: 29$ & $00: 33$ & $01: 48$ & $00: 23$ & $00: 29$ & 5.80 & \begin{tabular}{|l|}
5.62 \\
\end{tabular} \\
\hline
\end{tabular}

The time clock for a cycle starts/ends when the skid steer loader leaving the "gravel" zone returns to the "gravel' zone. Since the last cycle may not include any loading further loading, the total number of complete cycles will be one less than the number of travels listed in Table 1. 


\section{Pradhananga and Teizer}

Throughout the day, the skid steer loader made nine trips between the "gravel" and the "excavator" zones. The average haul and return times were 29 and 33 seconds, respectively. The return time was slightly higher than the haul time because the skid steer had to travel in reverse from the "excavator" back to "gravel" zone. The average loading and unloading times were 29 and 23 seconds, respectively. One can assume that loading takes more time than unloading material.

\section{Fixed Zone to Dynamic Zone (defined by a user, manually)}

The left image in Figure 6 shows a loader that delivered gravel from "gravel" zone to an excavator tagged with GPS data logging unit. While the loader continues to deliver gravel to the excavator, it should be noted that the excavator moved its position from "position 1" to "position 2" (see Figure 6 (left)) during the course of the data collection. This example demonstrates a case where the excavator position changed only once.

The results show that the loader made 21 trips between the "gravel" and the "excavator" zones. A 15 $m$ radius around the position of the excavator defined the unloading zone. Only cycles in which haul and return time were less than 10 minutes were considered. All other travels were discarded as they most likely involved other work activities of the loader. As explained, the excavator changed from "position 1" to "position 2" during the course of data collection. It was observed that the average haul and return time was 58 and 38 seconds, respectively. Since no significant change in the haul or return time for cycles to "position 1" or "position 2" was noticed, it was determined that the speed of the loader to position 2 increased to compensate for the time loss related to a larger distance. The variation of the haul and return time was high compared to the first case. The average cycle time was 3 minutes and 10 seconds. The average loading time was 1 minutes and 13 seconds while the average unloading time was 19 seconds. Loading time is the time taken by the loader to load the gravel but in this analysis, it started/ended at the moment the loader entered/left the "gravel" zone. It is likely that the loading/unloading time also includes some preparation time.
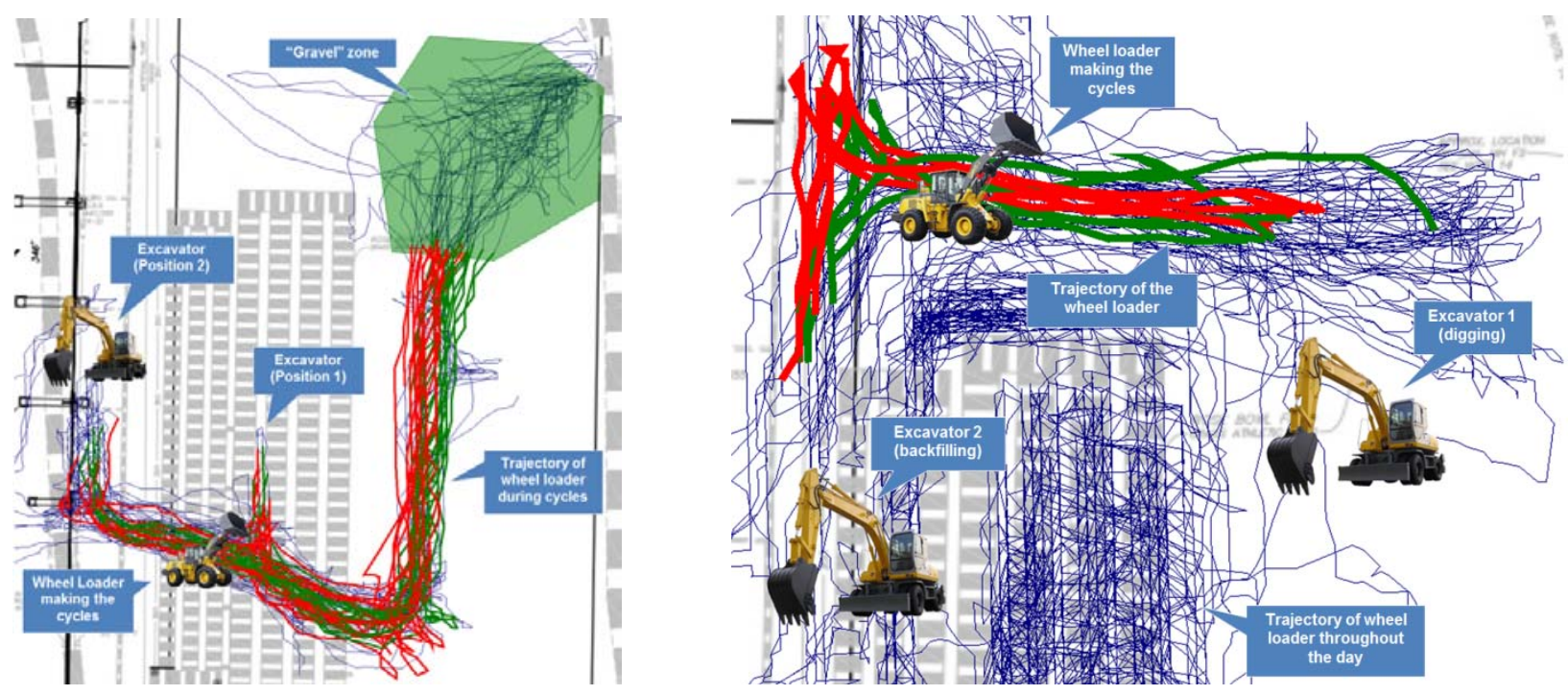

Figure 6: Cycle analysis: fixed zone to dynamic zone (left) and dynamic zone to dynamic zone (right).

\section{Dynamic Zone to Dynamic Zone (defined by a user, manually)}

A wheel loader hauling earth from one excavator to another is shown in Figure 6 (right). The first excavator piled earth that a second excavator used for backfilling. Since the loader was not in operation most of the time on the observation day its operator was tagged. A $15 \mathrm{~m}$ radius around each excavator was considered as loading and unloading zone. The trajectories of the loader during the time span of hauling earth material lasted from 1:30-2:00 p.m. and are illustrated in Figure 6 (right). 


\section{Pradhananga and Teizer}

A total of five trips were made during the time of observation. Average hauling and return time were found to be 27 and 26 seconds, respectively. The haul and return time were somewhat consistent as the travel segment was short. The average cycle time was 1 minutes and 44 seconds. The loading and unloading time were found to be 42 and 7 seconds, respectfully. The loading time is likely to be higher as normal as the loader had to wait for the excavator to pile up the earth and load it while unloading did not require any preparation time.

\subsection{Results to Zone and Speed Analysis}

The developed approach so far demonstrated that users can specify work zones and analyze cyclic equipment tasks. Zone detection can be automated if enough criteria are provided. The following scenario presents the analysis of a skid steer loader during the course of a work day. Data to a total of 11 hours and 59 minutes was available (08:02:59 a.m. to 08:01:58 p.m.). Figure 7 illustrates different work zones and grey-shaded trajectories of a skid steer loader. The results are summarized in Table 2.

Table 2 shows that the skid steer loader spent 8 hours in the work zone, 1 hour and 33 minutes in a parking zone, and 2 hours and 22 minutes in other zones. The time spent in the work zones only indicates that the skid steer was in the working area. This does not imply that the equipment was actually utilized. Hence, an analysis determined the amount of time it was actually in motion.

Table 3 shows that the skid steer was stationary for nine hours and 26 minutes during the 12 hour work day (or $79 \%$ of the total day). Out of the eight hours the skid steer loader spent inside the work zone, five hours and 50 minutes (or $73 \%$ of the time inside the work zone) was stationary time. Similar analysis was done for speed ranges from $0-2 \mathrm{~km} / \mathrm{h}, 2-5 \mathrm{~km} / \mathrm{h}, 5-10 \mathrm{~km} / \mathrm{h}$ and more than $10 \mathrm{~km} / \mathrm{h}$. This comparison was done to compare the proportion of time traveled by the skid steer inside and outside the working zone. The statistics shows that it traveled at the speed of $0-2 \mathrm{~km} / \mathrm{h} 4 \%$ of the entire work day and $5 \%$ of the time inside the working zone. The same analysis was done for travel speeds between $2-5 \mathrm{~km} / \mathrm{h}$, $5-10 \mathrm{~km} / \mathrm{h}$, and greater than $10 \mathrm{~km} / \mathrm{h}$. The results can be read in Table 3 . The comparison showed that the proportion of speed distribution at which the equipment traveled inside or outside the working zone was not significantly different.

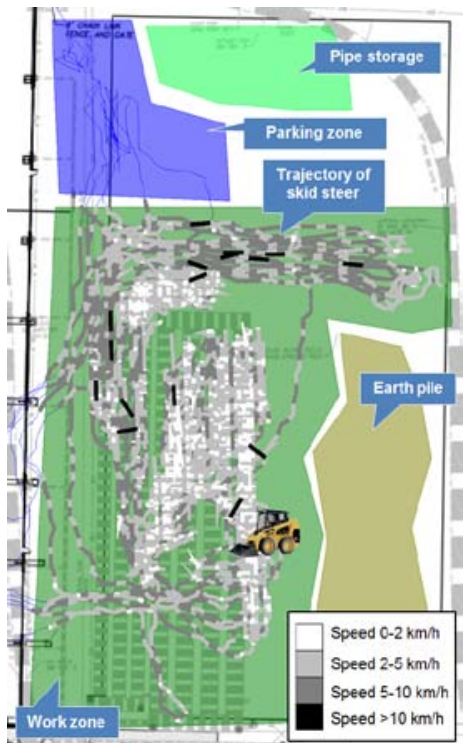

Figure 7: Zone and speed analysis.
Table 2: Summary of zone analysis.

\begin{tabular}{|l|l|l|}
\hline Type of Zone & $\begin{array}{l}\text { Entries in zone } \\
{[\text { No.] }}\end{array}$ & $\begin{array}{l}\text { Time spent in zone } \\
{[\mathrm{HH}: \mathrm{MM}: \mathrm{SS}]}\end{array}$ \\
\hline Work Zone & 10 & $08: 03: 15$ \\
\hline Parking Zone & 4 & $01: 33: 12$ \\
\hline $\begin{array}{l}\text { Other than work } \\
\text { and parking } \\
\text { Zone(s) }\end{array}$ & & $02: 22: 33$ \\
\hline Total time & & $11: 59: 00$ \\
\hline
\end{tabular}

Table 3: Summary of speed analysis.

\begin{tabular}{|l|l|l|l|l|}
\hline \multirow{2}{*}{$\begin{array}{l}\text { Speed } \\
{[\mathrm{km} / \mathrm{h}]}\end{array}$} & \multicolumn{3}{|l|}{\begin{tabular}{l} 
All day \\
\cline { 2 - 5 } \\
{$[$ Time }
\end{tabular}} & Work Zone \\
\hline 0 & $09: 25: 55$ & 78.71 & $05: 49: 45$ & 72.37 \\
\hline $0-2$ & $00: 27: 23$ & 3.81 & $00: 24: 49$ & 5.14 \\
\hline $2-5$ & $01: 20: 08$ & 11.15 & $01: 09: 53$ & 14.46 \\
\hline $5-10$ & $00: 45: 09$ & 6.28 & $00: 38: 32$ & 7.97 \\
\hline$>10$ & $00: 00: 24$ & 0.06 & $00: 00: 16$ & 0.06 \\
\hline Total & $11: 58: 59$ & 100.00 & $08: 03: 15$ & 100.00 \\
\hline
\end{tabular}




\section{Pradhananga and Teizer}

\subsection{Proximity Analysis Between Two Resources}

Table 4 shows the result of the proximity analysis between a skid steer and an excavator for an entire day. The same 12-hour dataset was used. The results show that the skid steer loader and the excavator came close in contact. For example, both pieces of equipment were 122 times closer than $10 \mathrm{~m}$ to each other on this specific work day. The total time spent in close contact to each other was 54 minutes and 46 seconds. The speed analysis resulted in information that the skid steer loader was in motion for 2 hours and 33 minutes on that work day. It spent approximately an hour near the excavator. Such knowledge shows that the skid steer loader was working near the excavator quite a bit of time. It should be noted that even if the equipment were stationary at a given time, this analysis would consider it as "in proximity" to the excavator. The minimum distance between the skid steer and excavator was $2.24 \mathrm{~m}$ at 8:11:10 a.m. Adding potential GPS measurement errors may slightly increase/decrease this distance.

Table 4: Proximity analysis between skid steer and excavator (threshold $=10 \mathrm{~m}$ ).

\begin{tabular}{|l|l|l|l|l|}
\hline $\begin{array}{l}\text { Occurrence of less } \\
\text { than 10m [No.] }\end{array}$ & $\begin{array}{l}\text { Start time } \\
\text { [HH:MM:SS }]\end{array}$ & $\begin{array}{l}\text { End time } \\
\text { [HH:MM:SS }]\end{array}$ & $\begin{array}{l}\text { Closest dis- } \\
\text { tance [m] }\end{array}$ & $\begin{array}{l}\text { Closest distance at time } \\
\text { [HH:MM:SS] }\end{array}$ \\
\hline 1 & $08: 11: 02 \mathrm{AM}$ & $08: 11: 14 \mathrm{AM}$ & 2.24 & $08: 11: 10 \mathrm{AM}$ \\
\hline 2 & $11: 18: 27 \mathrm{AM}$ & $11: 18: 33 \mathrm{AM}$ & 8.90 & $11: 18: 31 \mathrm{AM}$ \\
\hline$\ldots \ldots$ & $\ldots \ldots$ & $\ldots \ldots$ & $\ldots \ldots$ & $\ldots \ldots$ \\
\hline$\ldots \ldots$ & $\ldots \ldots$ & $\ldots \ldots$ & $\ldots \ldots$ & $\ldots \ldots$ \\
\hline 121 & $06: 48: 17 \mathrm{PM}$ & $06: 48: 46 \mathrm{PM}$ & 3.01 & $06: 48: 39 \mathrm{PM}$ \\
\hline 122 & $07: 31: 06 \mathrm{PM}$ & $07: 36: 54 \mathrm{PM}$ & 6.39 & $07: 36: 42 \mathrm{PM}$ \\
\hline
\end{tabular}

\section{6}

\section{RELEVANCE TO SIMULATION}

The presented analyses have potential to significantly impact on designing realistic simulation models and validating existing models. The analyses has been discussed along with its relevance to simulation.

\subsection{Analysis of Cyclic Activities}

Simulation of cyclic analysis requires a good understanding of all the components of a cycle, namely, load time, haul time, unload time, and return time. The results obtained from a simulation model depend upon these inputs. Like any computer model, garbage-in-garbage-out also applies to simulation models. That means, however robust a simulation model is, if the values of input parameters are not realistic, the output will not be realistic. Hence, the proposed approach can be implemented to check the validity and formulate a feedback mechanism to improve existing simulation models. The input parameters are calculated based on actual data from the site. Input modeling can be done on the collected data to obtain realistic values and statistical distribution of the parameters. Input modeling includes histogram analysis and goodness-of-fit tests for possible statistical distribution. It is also equally important to choose appropriate type of cycle for realistic results. If we consider a trenching operation where an excavator is excavating a trench and a dump truck is dumping the earth to a specific area, static to dynamic cycle should be chosen. It is also likely that the cycle time will change gradually as the trenching operation progresses. However, for a case of an excavator loading a dump truck to haul a designated earth pile to a backfilling zone, static to static cycle should be considered. Here, the cycle time should remain more or less constant.

\subsection{Zone and Speed Analysis}

Availability and working time of crucial equipment are important parameters for a simulation model. Availability of equipment at a specific zone can be determined using zone analysis. For a piece of equipment to be functional, it should not only be available but also be in operation. This approach considers movement of the equipment to analyze its operation time. Currently, only speed of the equipment has been considered in this paper as an indication of equipment being in operation while other parameters like orientation are also equally important. Activities should be simulated based on the availability of the 
equipment. Alternatively, if critical equipment needs to be utilized for different activities on a particular day, its utilization can be optimized by simulating its operation time to different activities so as to maximize productivity and minimize cost. This analysis can be used for cross checking actual site condition with simulation model in that case.

\subsection{Proximity Analysis Between Two Resources}

Proximity analysis can give valuable information about congestion on site. For example, proximity analysis among dump trucks can give an insight on the area where they come closer to each other than the distance desired for smooth cycles. The area where such proximity breaches happen can be detected and simulation model can be modified to address congestion in that zone. Analysis of a dump truck's speed can yield waiting times. Based on the location of the zone, traffic control plan(s) can be revised to avoid congestion or allocation of waiting time might be required at those zones to represent the actual site condition. However, all proximity conditions might not be congestion. Considering a two way path comprising both hauling and return path, the dump trucks may come close when they are passing besides each other in opposite direction. In this case speed analysis will be required for detecting congestion. In case of a dump truck waiting to enter a narrow hauling path in which only one vehicle can pass at a time, zone as well as proximity analysis needs to be implemented together to determine congestion and waiting time.

\section{CONCLUSIONS}

This paper demonstrated the use of GPS data logging technology for tracking and analyzing operation of equipment resources on a construction site. The developed approach presents new findings on how such spatio-temporal data can be analyzed. Applications for construction simulation, job site layout analysis, productivity, and safety analysis were discussed. Specifically, this paper presented several cases with data obtained from continuously tracking resources. It was shown that once data is processed it can be used for understanding the utilization of construction equipment as well as analyzing working conditions on a site. A user interface was created that allows manual and automatic identification of work zones. Data to equipment cycles was collected and analyzed using manual and automated work zone detection approaches. Additionally, equipment position and speed was analyzed to determine the proximity of equipment to others. Based on the findings, pro-active measures (leading indicators) can be taken to better organize job site layout, equipment operation and utilization, and prevent hazards on a job site. Future work is necessary to develop a breadth of criteria that allow reliable analysis of location tracking data. Further applications needs to be developed that allow decision makers at all levels in construction take advantage of the knowledge that is built upon the information that can be gathered. Education and training tools are expected to greatly advance the field of site preparation, planning, and controlling, including pre-task work planning and job site safety analysis.

\section{REFERENCES}

Behzadan, A. H., Aziz, Z., Anumba, C. J. and Kamat, V. R. 2008. "Ubiquitous location tracking for context-specific information delivery on construction sites.", Automation in Construction, 17, 737-748.

Cat. 2012. Accugrade ${ }^{\mathrm{TM}}$ Grade Control System, Accessed March 4, 2012. http://www.cat.com/cda/layout?m=37483\&x=7\&f=219543.

Cheng, T., Venugopal, M., Teizer, J. and Vela, P. A. 2010. "Performance evaluation of ultra wideband technology for construction resource location tracking in harsh environments.", Automation in Construction 20, 1173-1184.

Chi, S. and Caldas, C.H. 2012. " Image-based safety Assessment: Automated Spatial Safety Risk Identification of Earthmoving and Surface mining Activities.", Journal of Construction Engineering and Management, 138(3), 341-351.

Construction Industry Institute. 2010. Guide to Activity Analysis, The University of Texas at Austin, College of Engineering, Implementation Report 252-2a. 


\section{Pradhananga and Teizer}

Costin, A., Pradhananga, N. and Teizer, J. 2012. "Leveraging passive RFID technology for construction resource field mobility and status monitoring in a high-rise renovation project", Automation in Construction, Elsevier, 24, 1-15.

Fosbroke D.E. 2004. NIOSH reports! Studies on heavy equipment blind spots and internal traffic control, 2004 Roadway Work Zone Safety \& Health Conference, Baltimore, MD, 2004, Accessed November 13, 2011. https://www.workzonesafety.org/files/documents/news_events/wz_ conference_2004/heavy_equipment.pdf.

Hildreth J., Vorster M. and Martinez J., 2005 "Reduction of Short-Interval GPS Data for Construction Operations Analysis", Journal of Construction Engineering and Management, 131, 920.

Hinze J. 2005 "Construction Safety in the $21^{\text {st }}$ Century", Keynote lecture 2, Third International Conference on Construction in the 21st Century (CITC-III), Advancing Engineering, Management and Technology,15-17, September 2005, Athens.

Li, H., Chen, Z., Yong, L. and Kong, S.C.W. 2005. "Application of integrated GPS and GIS technology for reducing construction waste and improving construction efficiency.", Automation in Construction 14 (2005) 323-331.

Oloufa, A. A., Ikeda, M. and Oda, H., 2002 "GPS Based Wireless Collision Detection of Construction Equipment.", In Proceedings of 19th ISARC, National Institute of Standards and Technology, Gaithersburg, Maryland. September 23-25, 461-466.

Peyret F., Bétaille D. and Hintzy G. 2000. "High-precision application of GPS in the field of real-time equipment positioning.", Automation in Construction, 9(3), 299-314.

Razavi, S. N. and Haas, C.T. 2010. "Multisensor data fusion for on-site materials tracking in construction.", Automation in Construction, 19, 1037-1046.

Ruß, G and Brenning, A. 2010. "Data Mining in Precision Agriculture: Management of Spatial Information", In Conference Proceedings Computational Intelligence for Knowledge-Based Systems Design, Lecture Notes in Artificial Intelligence, 6178, Berlin, Heidelberg, 350-359.

Teizer, J., Allread, B. S. and Mantripragada, U. 2010. "Automating the blind spot measurement of construction equipment." Automation in Construction, 19, 491-501.

Xie, H., AbouRizk, S. and Fernando, S. 2011. "Integrating Realtime Project Progress Input Into A Construction Simulation Model”, In Proceedings of the 2011 Winter Simulation Conference, edited by S. Jain, R.R. Creasey, J. Himmelspach, K.P. White, and M. Fu, 3448-3459, Phoenix, AZ: Institute of Electrical and Electronics Engineers.

Zheng, Y., Chen, Y., Li, Q., Xie, X. and Ma, W. 2012. "Understanding Transportation Modes Based on GPS Data for Web Applications.", ACM Transactions on the Web, 4 (1).

\section{AUTHOR BIOGRAPHIES}

JOCHEN TEIZER is an Associate Professor in the School of Civil and Environmental Engineering at the Georgia Institute of Technology. He is the founder and director of the Real-time Project Information and Decision Systems Laboratory (RAPIDS) at Georgia Tech. The RAPIDS laboratory (http://www.rapids.gatech.edu) is a unique facility in the United States that focuses on developing and applying innovative technologies and methods to improve the construction safety performance. His email address is teizer@gatech.edu.

NIPESH PRADHANANGA is a Ph.D. Candidate in the School of Civil and Environmental Engineering at the Georgia Institute of Technology. His research interests are in capturing and processing real-time data from construction resources with an objective of making construction sites safer and more productive. His email address is nipesh@gatech.edu. 